\title{
Early Changes in Ventricular Repolarization after Thrombolytic Therapy in Patients with Acute Myocardial Infarction as Indicators for Prediction of Epicardial Coronary Artery Reperfusion
}

\author{
Aly Mohamad Hegazy ${ }^{a}$ Bader A. Abdulkader ${ }^{b}$ Mousa A.J. Akbar ${ }^{c}$ \\ Laila Soud El-Enezi ${ }^{\text {b }}$ \\ ${ }^{a}$ Non-Invasive Cardiac Laboratory, ${ }^{b}$ Department of Medicine, Farwania Hospital, and ${ }^{\mathrm{C} C o r o n a r y}$ Care Unit, \\ Sabah Hospital, Kuwait
}

\section{Key Words}

Electrocardiogram - Ventricular repolarization - Myocardial infarction - Thrombolytic therapy

\begin{abstract}
Objectives: To investigate the relationship between early Twave inversion after thrombolytic therapy and the likelihood of successful epicardial coronary reperfusion. Subjects and Methods: Thrombolytic therapy was given to $195 \mathrm{pa}-$ tients with ST segment elevation due to acute anterior myocardial infarction (AMI). Coronary angiography was performed. Receiver operating characteristic (ROC) curve (grade of sensitivity versus false positive) was calculated using likelihood ratio method to identify the ideal cut-off values of the ventricular repolarization variables. Results: Predictive indices showed $80 \%$ sensitivity, $83 \%$ specificity, $81 \%$ accuracy, $88 \%$ positive predictive value and $71 \%$ negative predictive value for early T-wave inversion after thrombolytic therapy. A good concordant agreement was noted between the data of coronary angiography and early T-wave inversion in the infarct-related ECG leads after thrombolysis (kappa coefficient $\kappa=0.876$ ). Stepwise multivariate analysis revealed that early T-wave inversion after thrombolytic therapy of AMI was significantly associated with a history of preinfarction angi-
\end{abstract}

na, residual infarct-related coronary artery stenosis $>50 \%$, short time to thrombolytic therapy $<90 \mathrm{~min}$, and evening time for occurrence of thrombolysis $(p<0.05)$. The ROC curve data analysis showed that early T-wave inversion amplitude after AMI had $87 \%$ sensitivity and $84 \%$ specificity for predicting successful reperfusion, with an ideal cut-off value of $7.2 \mathrm{~mm}$, while time of T-wave inversion had $80 \%$ sensitivity and $79 \%$ specificity, with an ideal cut-off value of $120 \mathrm{~min}$. Conclusion: The data indicate that early inversion of T wave after AMI is a statistically significant independent variable in predicting successful epicardial coronary thrombolysis status.

Copyright $\odot 2007$ S. Karger AG, Basel

\section{Introduction}

Ganz et al. [1] and Rentrop et al. [2] described four features commonly associated with recanalization of an occluded infarct-related artery following myocardial infarction and consequent ST elevation treated with intracoronary streptokinase: relief of chest pain, resolution of ST elevation on surface electrocardiogram (ECG), rapid release (early washout) of biochemical markers from injured myocytes and development of reperfusion arrhyth-

\section{KARGER}

Fax +41613061234

E-Mail karger@karger.ch

www.karger.com
(C) 2007 S. Karger AG, Basel

1011-7571/07/0162-0124\$23.50/0

Accessible online at:

www.karger.com/mpp
Dr. Aly Hegazy, MB, BCh, MS, PhD

Non-Invasive Cardiac Laboratory, Department of Medicine, Farwania Hospital PB 18373

Kuwait 81004 (Kuwait)

Tel. +965 488 2379, Fax +965 483 7079, E-Mail alymhd57@hotmail.com 
mias. Resolution of chest pain may be influenced by subjective factors such as age, gender, cultural beliefs and administration of pain-relieving drugs, but chest pain resolution has not proven sufficiently accurate to guide clinical decision making [3]. Accelerated idioventricular rhythm, the classic reperfusion arrhythmia, is specific but not sensitive to infarct-related artery patency; thus, the absence of accelerated idioventricular rhythm is of little clinical value [4]. Successful thrombolytic therapy is associated with rapid resolution of ST segment and, in a substantial proportion of patients there is early and rapid development of new pathologic $\mathrm{Q}$ and $\mathrm{R}$ wave amplitude loss [5]. Although a great deal of attention has been paid to the significance of early changes in the ST segment after thrombolytic therapy [4], little importance is given to early changes in the $\mathrm{T}$ wave [6]. Therefore the aim of this study was to investigate the relationship between early T-wave inversion after thrombolytic therapy and the likelihood of successful epicardial coronary reperfusion.

\section{Subjects and Methods}

\section{Subjects}

All patients admitted to the Coronary Care Unit were evaluated: clinical history, physical examination, 12-lead ECG, plain chest X-ray and routine laboratory investigations. Of these, 195 with acute anterior myocardial infarction (AMI) were included in the study. Those with left bundle-branch block, strain patterns due to left ventricular hypertrophy, atrial fibrillation and those who had any contraindications to thrombolytic therapy were excluded.

\section{Thrombolytic Therapy}

One hundred and ten patients received intravenous (i.v.) streptokinase infusion (1.5 million U over $60 \mathrm{~min}$ ) followed by i.v. heparin infusion while 85 were treated with recombinant tissue plasminogen activator (100 $\mathrm{mg}$ i.v. over $90 \mathrm{~min}$ ).

\section{Electrocardiogram}

On admission to the Coronary Care Unit, after thrombolytic therapy, a standard 12-lead ECG was recorded hourly for $3 \mathrm{~h}$ and every $3 \mathrm{~h}$ thereafter during the first $24 \mathrm{~h}$, after which it was recorded daily throughout the hospital stay. The ECG was reviewed for the presence of T-wave inversion in at least half of those leads in which initial ST segment elevation was observed on the admission ECG. The T wave was considered inverted if it was monophasic negative with amplitude $>1 \mathrm{~mm}$ [7].

Coronary Angiography and Grading of Collateral Circulation

Coronary stenosis was quantified visually to determine the extent and severity of coronary lesions and to locate those lesions with residual coronary stenosis. Luminal narrowing of $>50 \%$ was considered a significant coronary artery lesion.
Infarct-related artery flow was quantitated using thrombolysis in myocardial infarction (TIMI) flow grades: TIMI $0=$ no perfusion, no flow beyond the occlusion; TIMI 1 = penetration without perfusion, slow and incomplete opacification of the vascular bed by contrast material; TIMI 2 = partial perfusion, slow but complete opacification of the vascular bed by contrast material with slower clearance, and TIMI 3 = complete perfusion, prompt and complete opacification of the vascular bed by contrast material with rapid clearance as in an uninvolved artery [8].

Collateral filling of the obstructed vessels was classified based on the presence and extent of epicardial filling by contralateral coronary artery injections as follows: class $0=$ no epicardial filling; class I = partial filling of the epicardial segment; class II = complete epicardial filling [9].

\section{Statistical Analysis}

Comparison between two groups was performed with $t$ test for continuous variables and chi-square test for categorical variables ( $p<0.05$ was significant and $p<0.01$ highly significant). A multivariate regression model identified possible independent variables associated with early T-wave inversion after thrombolysis of AMI. The predictive value of early T-wave inversion after AMI to detect better epicardial coronary artery perfusion TIMI grades was assessed by estimating the predictive indices and kappa concordance coefficient value to determine the overall agreement with the data obtained from coronary angiography.

Receiver operating characteristic (ROC) curve identified the sensitivity and false positive values of the variable to detect usefulness of early T-wave inversion after AMI for prediction of successful coronary thrombolysis.

\section{Results}

Significantly more patients (66\%) admitted in the evening had early T-wave inversion after thrombolytic therapy compared to those who were admitted in the morning $(23 \%, \mathrm{p}<0.05)$. Among the patients $(66 \%)$ with early T-wave inversion the percentage of those who had a history of preinfarction angina was higher than among those $(28 \%)$ without $\mathrm{T}$-wave inversion $(\mathrm{p}<0.05)$.

\section{Presenting ECG}

All the patients presented with ST segment elevation $>2 \mathrm{~mm}$ in the chest leads; 72 of them had ST segment elevation in V1 and V2, 81 ST segment elevation in V1-V5 and 42 ST segment elevation in V3-V5.

\section{ECG after Thrombolysis}

Of the 102 patients who had T-wave inversion after thrombolysis, 66 (64.7\%) had T-wave inversion within $3 \mathrm{~h}$ and $36(35.3 \%)$ after $3 \mathrm{~h}$ from initiation of thrombolysis. Changes to ECG tracing before and after thrombolysis in patients with and without early T-wave inversion 
Fig. 1. Changes in ECG tracing before (upper ECG) and after thrombolysis (lower ECG) in patients with early T-wave inversion. The depth of the $\mathrm{T}$ wave was measured after the raised ST segment and not from the isoelectric line.
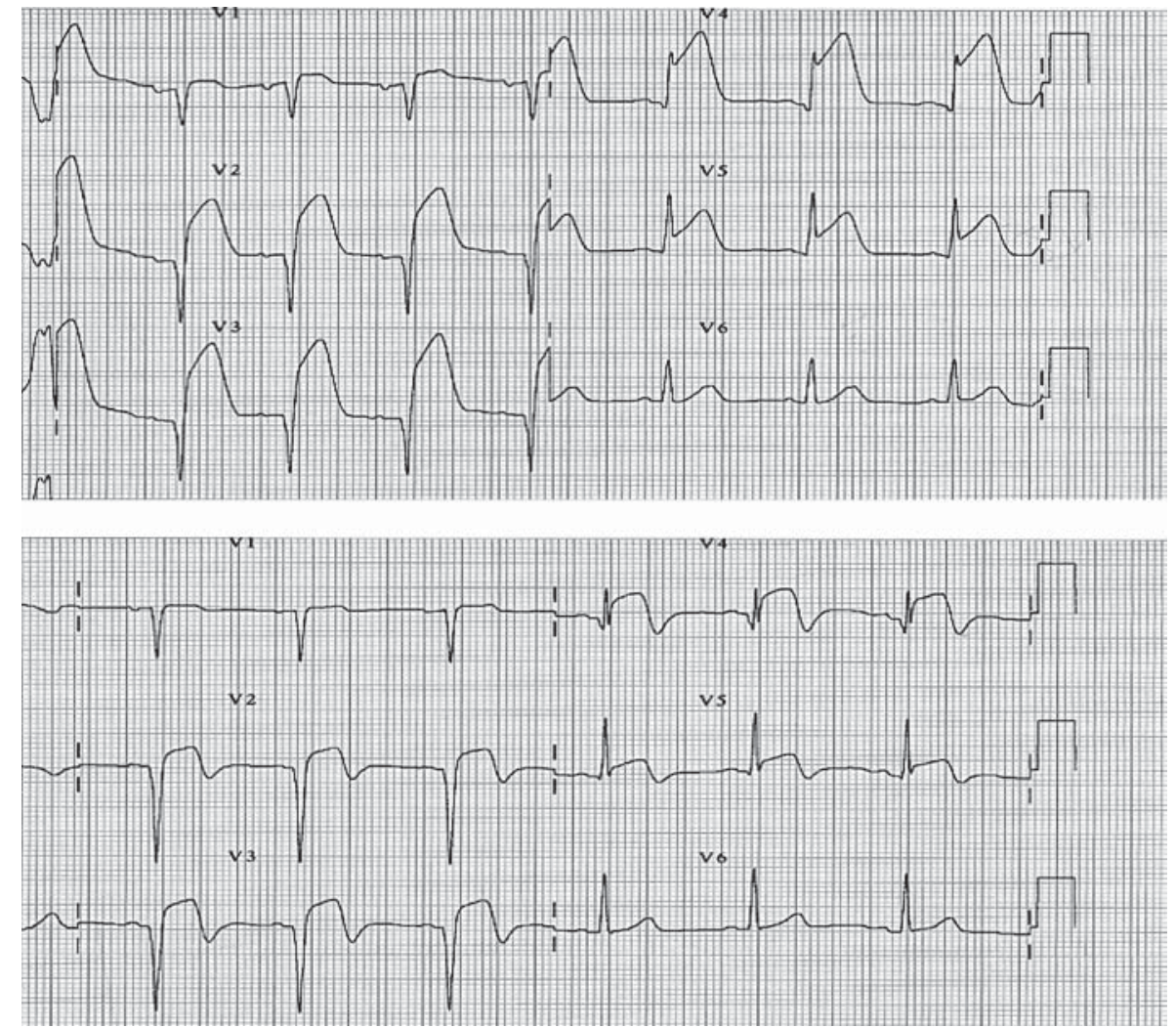

are shown in figures 1,2 . For the baseline/90-min ST segment resolution, a resolution $>50 \%(3.4 \pm 1.1$ vs.1.2 \pm $0.6 \mathrm{~mm}, \mathrm{p}<0.05$ ) was noted in patients with early T-wave inversion, but in those patients without early T-wave inversion there was $<50 \%$ resolution $(2.9 \pm 1.4$ vs. $1.7 \pm$ $0.8 \mathrm{~mm}, \mathrm{p}<0.05)$.

\section{Coronary Angiography}

A significantly greater number of patients with singlevessel disease had early T-wave inversion compared to those without T-wave inversion [49 (68\%) vs. 34 (54\%), $p<005]$ ), but there was no significant difference among those with two- and three-vessel lesions $(\mathrm{p}=\mathrm{NS})$. There was a significant decrease in the residual coronary stenosis in patients with early T-wave inversion compared to those without early T-wave inversion after thrombolysis $(65.4 \pm 12.7 \%$ vs. $80.2 \pm 10.3 \%, p<0.05)$, but there was no significant difference between both groups with regard to the site of the causative lesion in the left anterior descending artery. Regarding the coronary collaterals, there was a significant difference between patients with early T-wave inversion compared to those without in both class $1(11,10.8 \%$ vs. $20,21.5 \%, \mathrm{p}<0.05)$ and class $2(15$, $14.7 \%$ vs. $8,8.6 \%, \mathrm{p}<0.05)$.

\section{Forward Stepwise Logistic Analysis}

Multivariate analysis revealed that early T-wave inversion after AMI was significantly associated with a history of preinfarction angina, residual infarct-related artery $>50 \%$, chest pain to thrombolytic therapy $<90 \mathrm{~min}$ and evening time of thrombolysis $(\mathrm{p}<0.05)$. However, there was no significant relationship with age, gender, diabetes mellitus status, hypertension, site of infarction, fibrinspecific thrombolytic therapy and coronary collaterals (table 1).

\section{Agreement and Reliability}

There was concordant agreement between coronary angiographic data and early T-wave inversion in the infarct-related ECG leads after thrombolysis $(\kappa=0.876)$. The predictive indices showed that early T-wave inversion is a valid indicator for predicting successful thrombolysis with high sensitivity ( $80 \%)$, specificity ( $83 \%)$, accuracy $(81 \%)$, positive predictive value $(88 \%)$ and negative predictive value $(71 \%)$.

\section{ROC Curve}

ROC curve data analysis showed that early T-wave inversion amplitude after AMI had $87 \%$ sensitivity and 
Fig. 2. Changes in ECG tracing before (upper ECG) and after thrombolysis (lower ECG) in patients without early T-wave inversion. The depth of the T wave was measured after the raised ST segment and not from the isoelectric line.
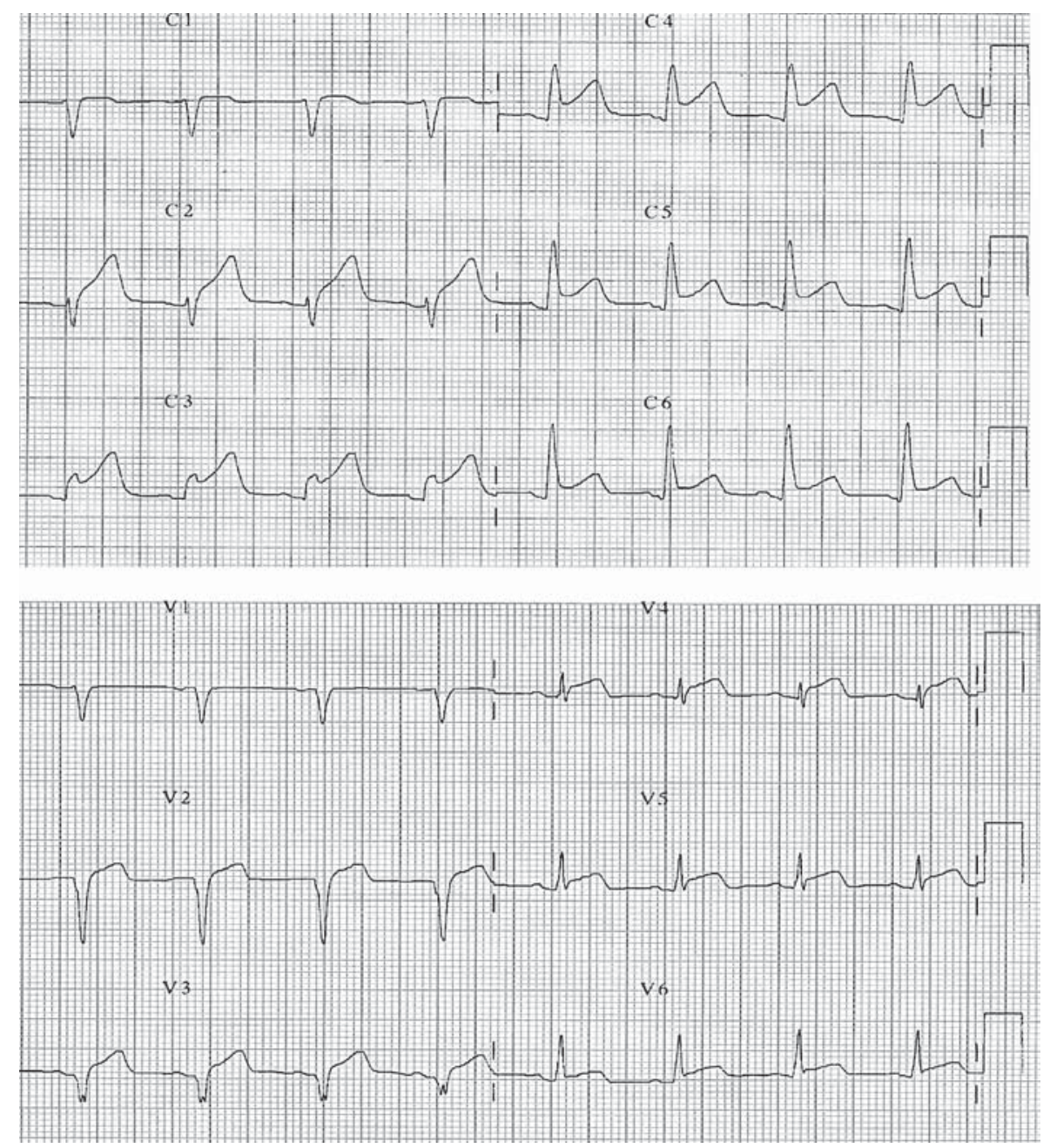

$84 \%$ specificity in predicting successful reperfusion, with an ideal cut-off value at $7.2 \mathrm{~mm}$ inversion. Time of T-wave inversion had $80 \%$ sensitivity and $79 \%$ specificity, with an ideal cut-off time at $120 \mathrm{~min}$. Early ST segment resolution had $84 \%$ sensitivity and $81 \%$ specificity for predicting successful reperfusion, with an ideal cut-off value of $>75 \%$ resolution. The time of ST segment resolution had $74 \%$ sensitivity and $72 \%$ specificity, with an ideal resolution time of $90 \mathrm{~min}$ (table 2).

\section{Discussion}

Our findings suggest that early (within $24 \mathrm{~h}$ ) inversion of T waves in infarct-related ECG leads after thrombolytic therapy is predictive of successful and effective epicardial coronary reperfusion. Early T-wave inversion was associated with more frequent and greater adequate patency of the infarct-related artery. Our findings are similar to those of Richardson et al. [6], who reported a significantly faster reduction of $\mathrm{T}$ wave amplitude, within $3 \mathrm{~h}$ after the initiation of thrombolytic therapy among patients with a patent infarct-related artery.

The early inversion of $T$ waves in association with successful thrombolysis and salvage of jeopardized myocardium can probably be explained by the special pattern of left ventricular innervation [10]. Sympathetic nerve fibers to the left ventricle travel in the subepicardium in a basal-apical course along with the coronary arteries [11]. Sympathetic denervation supersensitivity occurs in the non-infarcted myocardium apical to the transmural myocardial infarction, which probably is due to a small increase in adenylate cyclase activity in the denervated apical regions. Because sympathetic denervation delays 
Table 1. Stepwise logistic multivariate analysis of early T-wave data of patients with and without inversion

\begin{tabular}{|c|c|c|c|c|c|}
\hline Independent variables & $\begin{array}{l}\text { Coef- } \\
\text { ficient }\end{array}$ & SE & $\mathrm{p}$ value & $\begin{array}{l}\text { Odds } \\
\text { ratio }\end{array}$ & $95 \% \mathrm{CI}$ \\
\hline \multicolumn{6}{|l|}{ Age } \\
\hline+5 years increment & 0.0657 & 0.0186 & NS & 0.893 & $0.125-1.691$ \\
\hline+10 years increment & 0.0983 & 0.0141 & NS & 0.721 & $0.278-1.235$ \\
\hline \multicolumn{6}{|l|}{ Gender } \\
\hline Male & 0.0301 & 0.0072 & NS & 0.861 & $0.221-1.405$ \\
\hline Female & 0.0611 & 0.0108 & NS & 0.799 & $0.373-1.304$ \\
\hline \multicolumn{6}{|l|}{ Diabetes mellitus status } \\
\hline Yes & 0.0873 & 0.0369 & NS & 0.793 & $0.121-1.326$ \\
\hline No & 0.0820 & 0.0174 & NS & 0.682 & $0.286-1.193$ \\
\hline \multicolumn{6}{|c|}{ Residual IRA coronary stenosis } \\
\hline$>50 \%$ & 0.3652 & 0.0343 & $<0.05$ & 2.521 & $1.617-3.595$ \\
\hline$<50 \%$ & 0.0497 & 0.0721 & NS & 0.832 & $0.271-1.496$ \\
\hline \multicolumn{6}{|c|}{ Time to thrombolytic therapy } \\
\hline$<90 \mathrm{~min}$ & 0.4815 & 0.0287 & $<0.05$ & 2.927 & $1.420-4.438$ \\
\hline$>90 \min$ & 0.0822 & 0.0995 & NS & 0.803 & $0.199-1.654$ \\
\hline \multicolumn{6}{|c|}{ Fibrin-specific thrombolysis } \\
\hline Yes & 0.0812 & 0.0369 & NS & 1.094 & $0.583-1.592$ \\
\hline No & 0.0845 & 0.0247 & NS & 0.987 & $0.256-1.634$ \\
\hline \multicolumn{6}{|l|}{ Preinfarction angina } \\
\hline Yes & 0.1934 & 0.0265 & $<0.05$ & 1.892 & $1.085-2.642$ \\
\hline No & 0.0794 & 0.0275 & NS & 0.973 & $0.421-1.476$ \\
\hline \multicolumn{6}{|c|}{ Time of day of thrombolysis } \\
\hline Morning (a.m.) & 0.0916 & 0.0169 & NS & 0.994 & $0.257-1.794$ \\
\hline Evening (p.m.) & 0.2197 & 0.0374 & $<0.05$ & 1.965 & $1.198-2.827$ \\
\hline
\end{tabular}

Table 2. ROC curve data to define the ideal cut-off values of the amplitude and time of T-wave inversion and ST segment resolution for prediction of better epicardial coronary artery perfusion grade after thrombolytic therapy

\begin{tabular}{lclllll}
\hline $\begin{array}{l}\text { Ventricular } \\
\text { repolarization variables }\end{array}$ & $\begin{array}{l}\text { Ideal cut-off } \\
\text { values }\end{array}$ & $\begin{array}{l}\text { Sensi- } \\
\text { tivity, } \%\end{array}$ & $\begin{array}{l}\text { Speci- } \\
\text { ficity, } \%\end{array}$ & $\begin{array}{l}\text { False } \\
\text { positive, \% }\end{array}$ & \multicolumn{2}{l}{\begin{tabular}{l} 
Likelihood ratio \\
\cline { 5 - 7 } positive
\end{tabular}} \\
\hline T-wave inversion & $7.2 \mathrm{~mm}$ & 87 & 82 & 18 & 4.83 & 0.158 \\
Time of T inversion & $120 \mathrm{~min}$ & 80 & 79 & 21 & 3.81 & 0.253 \\
ST segment resolution & $>75 \%$ & 84 & 81 & 19 & 4.42 & 0.197 \\
Time of ST resolution & $90 \mathrm{~min}$ & 74 & 72 & 28 & 2.64 & 0.361 \\
\hline
\end{tabular}

Ideal cut-off value: high detection rate (sensitivity) with low false positive, false positive: 1 - specificity.

repolarization, the ECG presentation of denervated myocardium in the facing ECG leads would result in early Twave inversion [12].

Andreotti et al. [13] found that in patients with AMI and a history of preinfarction angina, thrombolytic ther- apy resulted in more rapid reperfusion and smaller infarcts. In the present study, the time of day when thrombolytic treatment was started was important: a greater number of the patients who had thrombolytic activity in the evening had early T-wave inversion (indicating effec- 
tive coronary thrombolysis) compared to those patients who presented in the morning. The findings in this study are in agreement with those of Braunwald [14]. A probable explanation is that both plasminogen activator inhibitor-1 (PAI-1) activity and tissue plasminogen activator (TPA) antigen levels appear to be lower in the evening, while TPA activity is higher, reflecting the important role of PAI-1 levels in regulating TPA activity [15].

Confounders and limitations of our study were that the relatively small number of patients who came from one center and that myocardial contrast echocardiogra- phy was not performed to clearly determine myocardial blood flow and perfusion.

\section{Conclusion}

Early inversion of T wave in patients with AMI treated with thrombolytic therapy may be an independent variable and a marker for prediction of successful thrombolysis.

\section{References}

1 Ganz W, Buchbinder N, Marcus H, Mondkar A, Maddahi J, Charuzi Y, O'Connor L, Shell W, Fishbein MC, Kass R, Miyamoto A, Swan HJC: Intracoronary thrombolysis in evolving myocardial infarction. Am Heart J 1981; 101:4-13.

-2 Rentrop P, Blanke H, Karsch KR, Kaiser H, Kostering H, Leitz K: Selective intracoronary thrombolysis in acute myocardial infarction and unstable angina pectoris. Circulation 1981;63:307-317.

$\checkmark 3$ De Lemos JA, Morrow DA, Gibson CM, Murphy SA, Rifai N, Tanasijevic M, Giugliano RP, Schuhwerk KC, McCabe CH, Cannon CP, Antman EM, Braunwald E for the TIMI 14 Investigators: Early noninvasive detection of failed epicardial reperfusion after fibrinolytic therapy. Am J Cardiol 2001;88:353358.

4 Shah PK, Cercek B, Lew AS, Ganz W: Angiographic validation of bedside markers of reperfusion. J Am Coll Cardiol 1993;21:5561.

5 Sadanandan S, Hochman J, Kolodziej A, Criger DA, Ross A, Sevester R, Wagner GS: Clinical and angiographic characteristics of patients with combined anterior and inferior ST segment elevation on the initial electrocardiogram during acute myocardial infarction. Am Heart J 2003;146:653-661.
-6 Richardson SG, Morton P, Murtagh JG, Scott ME, O'Keeffe B: Relation of coronary arterial patency and left ventricular function to electrocardiographic changes after streptokinase treatment during acute myocardial infarction. Am J Cardiol 1988;61:961-965.

-7 Wong CK, French JK, Aylward PE, Frey MJ, Adgey AAJ, White HD: Usefulness of the presenting electrocardiogram in predicting successful reperfusion with streptokinase in acute myocardial infarction. Am J Cardiol 1999;83:164-168.

8 Barcin C, Denktas AE, Garratt KN, Higano ST, Holmes DR, Lerman A: Relation of thrombolysis in myocardial infarction (TIMI) frame count to coronary flow parameters. Am J Cardiol 2003;91:466-469.

-9 Stone DA, Corretti MC, Hawke MW: The influence of angiographically demonstrated coronary collaterals on the results of stress echocardiography. Clin Cardiol 1995; 18: 205-208.
10 Matetzky S, Barabash GI, Shahar A, Rabinowitz B, Rath S, Zahav YH, Agranat O, Kaplinsky E, Hod H: Early T wave inversion after thrombolytic therapy predicts better coronary perfusion: clinical and angiographic study. J Am Coll Cardiol 1994;24: 378-383.

11 Geis WP, Kaye MP: Distribution of sympathetic fibers in the left ventricular epicardial plexus of the dogs. Circ Res 1968;22:315323.

12 Kammerling J, Green FJ, Watanabe AM, Inoue H, Barber MJ, Henry DP, Zipes DP: Denervation supersensitivity of refractoriness in noninfarcted areas apical to transmural myocardial infarction. Circulation 1987;76: 383-393.

13 Andreotti F, Pasceri V, Hackett DR, Davies GJ, Haider AW, Maseri A: Preinfarction angina as a predictor of more rapid coronary thrombolysis in patients with acute myocardial infarction. N Engl J Med 1996;334:712.

14 Braunwald E: Morning resistance to thrombolytic therapy. Circulation 1995;91:16041606.

15 Angleton P, Chandler WL, Schamer G: Diurnal variation of tissue - type plasminogen activator and its rapid inhibitor (PAI-1). Circulation 1989;79:101-106. 